\title{
Prevention of injury-related knee osteoarthritis: opportunities for the primary and secondary prevention of knee osteoarthritis
}

\author{
Charles R Ratzlaff*1,2 and Matthew H Liang ${ }^{3,4}$
}

\begin{abstract}
Where risk factors have been identified in knee and hip osteoarthritis $(\mathrm{OA})$, with few exceptions, no prevention strategies have proven beneficial. The major risk factors for knee $O A$ are advanced age, injury and obesity. However, there is limited or no evidence that they are modifiable or to what degree modifying them is effective in preventing development of knee OA or in preventing symptoms and progressive disease in persons with early $\mathrm{OA}$. The notable exception is the growing epidemic of (sports) injury related knee OA. This review details the biological and clinical data indicating the efficacy of interventions targeting neuromuscular and biomechanical factors that make this subset of $O A$ an attractive public health target, and highlights research opportunities for the future.
\end{abstract}

\section{Introduction}

Osteoarthritis (OA) is the most important rheumatic disease affecting mankind. Where risk factors have been identified, such as in knee and hip OA, with few exceptions, no prevention strategies are well substantiated enough or have proven benefit to justify widespread dissemination. The major risk factors for knee OA are advanced age, injury and obesity [1]. However, there is limited or no evidence that they are modifiable or to what degree modifying them is effective or what this would cost in primary prevention (avoiding development of knee OA) or secondary prevention (detecting knee OA early to treat to prevent symptoms and progressive disease).

The notable exception is the growing epidemic of (sports) injury related knee OA. The purpose of this

*Correspondence: cratzlaf@interchange.ubc.ca

'School of Population and Public Health, University of British Columbia, 5804 Fairview Avenue, Mather Building, Vancouver, British Columbia, Canada V6T 1 Z3 Full list of author information is available at the end of the article review is to detail the biological and clinical data that make this subset of $\mathrm{OA}$ an attractive public health target.

Joint injury increases the risk of knee osteoarthritis The incidence and prevalence of severe knee injuries requiring medical attention are not well documented. The differential diagnosis of knee injuries includes contusion, subchondral or chondral injury with and without meniscal tear and with and without ligamentous injury or complete tear. In the best studied sports injuries, even injury not precipitating a medical visit appears to be a risk factor for knee OA; the rate is high and increasing worldwide.

Meniscus injuries are common in athletes and the general population [2,3]. Lohmander and colleagues [2] estimate that the cumulative population risk of an anterior cruciate ligament (ACL) injury between 10 and 64 years of age is about $5 \%$ based on MRI findings of the acutely injured knee, and for meniscus injury leading to surgery is at least $15 \%$. The incidence of ACL tears is unknown but the MRI-confirmed incidence has been reported at 81 per 100,000 in a hospital-based study [4], while a population-based study estimated rates 50 to $100 \%$ higher [5]. The true incidences of both meniscal and ligamentous injuries are likely to be higher since injuries are sometimes unreported, undiagnosed, or diagnosed without MRI.

Over the past two decades there has been an alarming increase in the rate of ACL injuries in young females in sports that involve cutting, jumping and pivoting. Adolescent and mature females in these sports have ACL injuries at a two- to eight-fold greater rate than males participating in the same sports [6-8]. This, along with a ten-fold increase in the number of women participating in sports since the inception of Title IX, has resulted in a dramatic increase in ACL injuries in females in the US [9].

The risk of knee OA from knee joint injury is high; approximately $50 \%$ of individuals with an ACL or meniscus tear develop knee OA [10-15]. A long-term prospective study indicated a relative risk for knee OA of approximately 5 for any previous injury of the knee [13]. 
Thelin and colleagues [16] found that knee joint injuries (and not the type of sport or other factors) accounted for all knee OA in a population-based case-control study of Swedish adults aged 51 to 70 years.

\section{Knee osteoarthritis after anterior cruciate ligament injury}

Individuals with ACL ruptures comprise an estimated 25\% of the overall knee OA population $[17,18]$. In male and female soccer players sustaining ACL tears, approximately $80 \%$ had radiographic OA 12 to 14 years later, irrespective of whether they had had surgical intervention; approximately $70 \%$ had functional limitations and reduced quality of life due to their knee $[10,12]$. While short- and midterm results of $\mathrm{ACL}$ reconstruction are satisfactory, 10 to 20 years after injury approximately $50 \%$ of those with ACL or meniscus tear have OA with associated pain and functional impairment [2]. Since ACL injury often occurs in young adulthood, OA development for many, if not most, is a distinct probability by their late 30 s or 40 s. Identification and implementation of disease-delaying treatment would be a major advance.

\section{Knee osteoarthritis and meniscal injury}

Degenerative meniscal pathology, that is, horizontal cleavages, flap or complex, are common - present in approximately a third of the general population over 50 years of age [3] - and are associated with increasing age, existing OA, and progression of OA [19]. Traumatic tears usually occur in younger individuals, increase the risk of OA [19] and appear to be an early event in the disease process [20].

Meniscectomy is a significant risk factor for knee OA the relative risk after total meniscectomy is six times greater than for un-operated controls [21]. In a prospective study of ACL-injured patients followed for 15 years, the primary risk factor for tibiofemoral OA was a prior meniscectomy [22].

The high incidence of OA after injury highlights a potential opportunity to improve population health and is a strong rationale to direct increased efforts toward primary prevention of knee injury and improved management of knee injury. A decade ago it was estimated that prevention of joint injuries would yield an approximately 14 to $25 \%$ reduction in OA prevalence [23]; with the alarming increase in female knee injuries in the past decade and an increased ability to detect injury using imaging, the risk of knee OA attributable to injury may be higher now.

\section{Primary prevention of injury-related knee osteoarthritis \\ Prevention of knee injuries}

It is possible to prevent a substantial number of knee injuries. Studies over the past decade have identified new and modifiable risk factors for knee injury and mechanisms of injury and provide evidence from multiple interventional prospective longitudinal studies and randomized controlled trials of how these factors can be modified.

Risk factors for knee injury include intrinsic (anatomic, neuromuscular, hormonal) and extrinsic factors (environmental, including knee bracing, shoe-surface interface, weather). The efficacy of knee bracing to prevent knee injury has been studied - mostly in American football and soccer players - and has shown contradictory results, with some studies reporting relative risk reductions in injury incidence of 10 to $50 \%$ [24-26], while others have reported increased risks of similar magnitude [27-30]. Compliance is a major issue as athletes may fear impaired performance and discomfort [27,31]. Rigorous randomized controlled trials are needed.

The playing surface and variable friction at the shoeground interface might be a determinant of knee injuries. Higher friction can result from surface type, shoe type and, in outdoor fields, ground hardness, dryness, grass cover and weather conditions. Studies of grass versus artificial turf in soccer and American football show that risk of knee injury is either not related to playing surface [32-34] or is slightly more common on older artificial surfaces [35]. In European team handball, floor type (artificial versus wooden) was a significant risk factor for ACL injuries in women [36,37].

Several studies demonstrate that knee injuries are increased on shoe-surface interfaces with higher friction (older artificial turf, dry hard fields) [35,38,39]. A 10-year study of 5,910 NFL games found that cold weather is associated with lower knee and ankle injury risk in outdoor stadiums with both natural grass and artificial turf, probably because of reduced shoe-surface traction $[38,39]$. A controlled biomechanical laboratory study showed that a high shoe-surface friction alters biomechanical movement patterns that increase the risk of ACL injury [40].

There is strong evidence for the role of intrinsic risk factors in the etiology of knee injury. Studies of the neuromuscular and biomechanical substrate of knee injuries show that most knee injuries are not the result of contact or collision, and that distinctive biomechanical patterns, such as excessive coronal plane motion (valgus collapse), are seen when the knee is injured [41-43]. Other kinematic factors associated with ACL injury include less knee flexion [43,44], decreased core and trunk control [45] and increased hip flexion, landing flatfooted and with less plantar flexion [42]. These observations led to the hypothesis that the ACL 'epidemic', especially in females, is primarily neuromuscular and biomechanical in nature and can be modified.

Prevention strategies based on neuromuscular training programs were subsequently designed to train athletes to 
land and decelerate in a more controlled fashion with reduced valgus collapse, increased knee flexion and improved trunk control, balance and proprioception. While there is not a consensus on program parameters, training is typically in 6- to 8 -week progressive sequences doing sport maneuvers in simulated game situations and/ or in 10- to 15-minute pre-game and pre-practice warmup routines. A meta-analysis examining the relative effectiveness of six interventions for reducing ACL injuries in females found that neuromuscular training may reduce ACL injuries if plyometrics, balance and strengthening are incorporated, and training sessions occur more than once per week and are a minimum of 6 weeks in length. The studies with the greatest impact on ACL risk incorporated high-intensity plyometric movements that progressed beyond footwork and agility [46].

From this has emerged a strong body of level 1 and 2 evidence that biomechanical risk factors for knee injury can be averted [47-49] and knee injuries substantially reduced [50-55]. Three recent large-scale randomized controlled trials [50-52] confirmed previous randomized controlled studies and support the utility of prevention programs in preventing knee and lower extremity injury [50-55]. The potential risk reductions for ACL injury are substantial, being 41 to $88 \%$ [50-52,54]. Of the few studies that have shown little or no effect on injuries, low athlete compliance likely played a role $[56,57]$.

\section{Prevention of knee osteoarthritis after knee injury}

Once the knee is significantly injured, the incidence of eventual knee OA is dramatically increased. It poses a challenge for the clinician and for those involved in injury prevention [58] to devise a secondary prevention strategy. There is reason to be cautiously optimistic that this is possible.

\section{Joint biomechanics and neuromuscular function in $O A$ development after injury}

Biomechanical factors may be a potent driver of OA after injury [59], but because of the long latency period in knee OA, study is difficult.

Knee alignment is one such biomechanical factor. Varus alignment is associated with medial compartment $\mathrm{OA}$ and valgus alignment with lateral compartment $\mathrm{OA}$, and there is strong circumstantial evidence that malalignment is important in disease progression [60]. Surgical re-alignment by osteotomy to unload the involved compartment appears to slow progression in the unloaded side and hastens progression on the loaded side in patients with uni-compartmental OA [61].

The injury itself alters biomechanics that may make the joint vulnerable to OA. Meniscus injury decreases the load bearing and shock absorbing function of the joint, increases tibial-femoral loading and decreases joint stability [62-64]. Damage to ligaments and the joint capsule may shift contact pressure of the joint surfaces during gait, which can result in degenerative metabolic changes in localized regions of cartilage [65].

Neuromuscular function is the complex interaction between sensory and motor pathways [66]. Significant knee injuries that damage ligaments and joint capsule can result in reduced muscle strength and activation [67-69] and may damage normal mechanoreceptors [70]. These are critical to normal joint protection whereby loads are anticipated and muscles and tendons assume the correct tension to deflect and distribute loads across the whole joint surface or lessen the rate with which the load is applied to the joint [71].

Individuals with knee injuries have a host of demonstrable but treatable neuromuscular impairments after injury, such as decreased quadriceps strength [69], poor lower limb positioning and proprioceptive deficiencies [72-74] and impaired postural control [66,75], that may be caused or exacerbated by arthrogenic inhibition and muscle guarding [68,76,77]. Without addressing these impairments, it is probable that even low or moderate activity after injury may increase risk of knee OA. Reduced neuromuscular control impairs normal joint protection mechanisms, leaving the joint vulnerable to increased loads and shear forces. These and shifts in contact distribution may play a role in cartilage degradation $[65,78,79]$.

\section{Can $O A$ be prevented or delayed after injury?}

Surgical treatment

Surgical reconstruction of the ACL restores short-term function and has good patient reported outcomes, but does not prevent knee OA $[2,10,12,80]$. While ACL reconstruction restores knee stability, it does not restore normal mechanics $[81,82]$, resulting in a shift in functional load bearing with rotational malalignment that may direct weight-bearing loads on regions of cartilage that are not able to withstand them $[82,83]$. While the reasons are not entirely clear, a contributing factor in surgical reconstructions may be the placement of the ACL graft, in particular the sagittal/coronal orientation [84]. Several longitudinal studies [85-87] have shown higher rates of both tibiofemoral OA and patellofemoral OA with a patellar tendon autograft versus a semitendinosis or gracilis autograft. There is evidence that traditional surgical decision making based on passive anterior knee laxity and pre-injury activity level are not good predictors of dynamic knee stability and function after surgery. Screening for neuromuscular function using such tests as the timed hop test and self-reported symptoms, such as knee giving-way, may be better predictors of function and help guide individualized patient management after ACL injury $[88,89]$. 
Randomized controlled trials investigating arthroscopic treatment of meniscal and chondral damage show no benefit of surgery over conservative treatment $[90,91]$ or placebo surgery [92]. Meniscectomy is associated with subsequent knee OA $[19,93]$ and the higher risk is associated with the greater amounts of meniscal tissue removed [11]. Arthroscopy, while shown to be promising in uncontrolled studies, is not efficacious in OA [94].

\section{Exercise therapy}

While exercise and neuromuscular training are theoretically beneficial and common treatment for knee injury, their efficacy in treating knee injury and preventing OA and the superiority of one form of exercise intervention over another are not supported by high quality trials $[95,96]$. Several observational studies have investigated conservative exercise-based management of ACL injury, or compared it to reconstructive surgery for longer term outcomes $[14,22,80]$. There is some evidence that nonoperative treatment may result in a lower rate of OA than surgical repair, particularly in patients willing to modify their activity. A prospective study [22] following up subjects 15 years after non-operative treatment of ACL injury found favorable functional outcomes and an exceptionally low incidence of radiographic knee OA. The primary treatment algorithm involved early activity modification and neuromuscular rehabilitation. The primary risk factor for OA was meniscectomy. Other observational studies have reported comparable outcomes with non-operative treatment versus reconstruction of ACL tears [97], some noting lower rates of $\mathrm{OA}$ in non-surgical groups $[10,14,98]$. In observational studies of surgery versus no surgery, unmeasured confounding, particularly confounding by indication, may bias the results. The first high quality randomized controlled trial comparing surgical and nonsurgical treatments for ACL tear was recently published [99], and concluded that structured rehabilitation with early reconstruction was not superior to a strategy of structured rehabilitation plus optional delayed ACL reconstruction. In the latter treatment arm, $60 \%$ of ACL reconstructions were avoided without adversely effecting outcomes at 2 years.

The role of exercise alone in preventing OA after injury has received limited study. Decreased muscle performance is a risk factor for OA in the young and middleaged adult [100]. Neuromuscular function of the quadriceps [101] and lower extremity performance [102] is impaired in subjects at risk for, but prior to onset of, radiographic OA, suggesting that muscle dysfunction precedes structural evidence of OA. There is evidence that moderate neuromuscular exercise improves joint symptoms and function and cartilage quality in those at high risk of developing OA [103]. From a population perspective, there is evidence that moderate physical activity and specific exercise regimens play a significant role in prevention of knee OA. Animal and human studies demonstrate that being physically active or specific exercises enhance cartilage properties, suggesting a pathway to prevent or delay OA [103-105]. An epidemiologic study of 55 to 75 year olds showed that regular, moderate physical exercise over the lifetime decreased the risk of severe knee OA [106]. Whether exercise could prevent knee OA after knee injuries, however, has not been adequately studied.

\section{Prevention of knee OA may start with the young: the role of physical activity and screening}

There is circumstantial evidence that knee OA prevention might start in childhood. The benefits of physical activity in childhood on bone mass persist into adulthood [107], but the effect on joints and cartilage is less well known. An MRI study of children aged 9 to 18 years found younger children, males and those undertaking more vigorous sports have substantially higher articular cartilage accrual rates [108]. While there are limitations to the available studies, the current evidence supports a prescription of vigorous physical activity for optimum joint development in children [109]. Vigorous activity would also reduce childhood and possibly adult obesity a leading risk factor for knee OA [1].

Citing the evidence that childhood and adolescent exercise and joint injury have long-term effects in adulthood, Nicholson and colleagues [110] have recently proposed a screening program of adolescents covering sports and activities, joint injury, body mass index and family history. There is evidence that screening may identify athletes at future risk of ACL rupture through assessment of neuromuscular activation in the lower limb [111] and core and trunk control [45], and standardized functional movement testing [112].

The identification of adolescents with early knee injury and those with potential neuromuscular and other risk factors might permit targeting of at-risk groups for exercise interventions, activity modification and education that may have an impact on prevention of knee OA, but this needs study.

\section{Future directions}

OA is the major public health problem in musculoskeletal medicine and the current evidence suggests that at least one subset, injury related knee OA, could be prevented and its incidence and prevalence markedly reduced. The strongest biological rationale is for implementing evidence-based interventions targeting neuromuscular and biomechanical factors. The attributable risk reduction from this alone can only be surmised at this time but is amenable to study. 
The most pressing need is to disseminate what we know works - strong evidence from multiple studies confirms that large numbers of knee OA cases are preventable. Translating knowledge of proven, injury prevention programs is a necessary next step. The richest target may be school- and university-aged students, reached through physical education curriculums and improved sports associations. An example is FIFA, the international governing body of the world's largest sport (by participation). They have studied and developed an injury prevention program - the FIFA 11 - which is simple and accessible worldwide through its Internet site [113].

The injured knee joint presents a rich opportunity for investigation of neuromuscular and biomechanical factors - the mechanical and physiological changes postinjury place these joints essentially in a pre-OA state, but with no apparent clinical or radiological signs of OA. There is a need for a neuromuscular screening tool to identify which knee-injured individuals are at highest risk for future OA development, and to determine neuromuscular and biomechanical signatures that predispose to OA. Target components include measures of muscle strength and activation, functional movement patterns, proprioception and alignment. Advanced imaging, including MRI and delayed gadolinium-enhanced MRI of cartilage (dGEMRIC), which can detect early incident OA, are available to use as a gold standard to validate such screening instruments. Although the evidence is incomplete, health care professionals should target kneeinjured individuals for primary prevention with respect to education, activity modification and the role of reestablishing neuromuscular function and exercise in surgical decision-making and rehabilitation.

There is a strong need to assemble early post-injury cohorts prior to OA development. Rigorous long-term randomized trials that evaluate surgical and conservative methods of treatment are required. In addition to established patient-reported outcomes, validated neuromuscular and biomechanical measures should be used since structural radiological change is a late sign.

Of particular interest, given the success of neuromuscular programs in altering risk factors and incidence of knee injury, is whether similar exercise strategies could be used to modify OA development and progression after injury. Similar trunk, hip and knee control strategies could be applied to knee-injured individuals.

Since most ACL and other types of knee injuries occur in the young population, the effectiveness of adolescent screening and the timing, nature, duration and compliance with intervention programs are other important areas of investigation.

Other chronic diseases with long latent periods (for example, osteoporosis, atherosclerotic vascular disease) have developed primary and secondary prevention
This article is part of a review series on New developments in osteoarthritis, edited by Martin Lotz and Stefan Lohmander. Other articles in the series can be found online at http://arthritis-research. com/series/osteoarthritis

strategies. OA has long been ignored. With new knowledge that goes beyond the description of risk factors, we have the opportunity to test a population strategy for one preventable subset. Knee injury prevention and injury management offer a significant opportunity to address knee OA at an earlier stage.

\section{Abbreviations}

$\mathrm{ACL}=$ anterior cruciate ligament; $\mathrm{MRI}=$ magnetic resonance imaging; $\mathrm{OA}=$ osteoarthritis.

\section{Competing interests}

The authors declare that they have no competing interests.

\section{Acknowledgements}

Supported by grants from the Molson Foundation, the Michael Smith Foundation for Health Research and a Canadian Institutes of Health Research Fellowship.

\section{Author details}

'School of Population and Public Health, University of British Columbia, 5804 Fairview Avenue, Mather Building, Vancouver, British Columbia, Canada V6T 1Z3. ${ }^{2}$ Arthritis Research Centre of Canada, Vancouver, 895 W. 10th Avenue, Vancouver, British Columbia, Canada V5Z 1L7. ${ }^{3}$ Division of Rheumatology, Immunology, and Allergy, Brigham and Women's Hospital, 75 Francis StreetPBB3, Boston, MA 02115, USA. ${ }^{4}$ Cooperative Studies Program, Massachusetts Veterans Epidemiology and Research Center, 150 South Huntington Avenue, Boston, MA 02130, USA.

\section{Published: 31 August 2010}

\section{References}

1. Zhang Y, Jordan JM: Epidemiology of osteoarthritis. Rheum Dis Clin North Am 2008, 34:515-529.

2. Lohmander LS, Englund PM, Dahl LL, Roos EM: The long-term consequence of anterior cruciate ligament and meniscus injuries: osteoarthritis. Am J Sports Med 2007, 35:1756-1769.

3. Englund M, Guermazi A, Gale D, Hunter DJ, Aliabadi P, Clancy M, Felson DT: Incidental meniscal findings on knee MRI in middle-aged and elderly persons. N Engl J Med 2008, 359:1108-1115.

4. Frobell RB, Lohmander LS, Roos HP: Acute rotational trauma to the knee: poor agreement between clinical assessment and magnetic resonance imaging findings. Scand J Med Sci Sports 2007, 17:109-114.

5. Granan LP, Bahr R, Steindal K, Furnes O, Engebretsen L: Development of a national cruciate ligament surgery registry: the Norwegian National Knee Ligament Registry. Am J Sports Med 2008, 36:308-315.

6. Myklebust G, Maehlum S, Engebretsen L, Strand T, Solheim E: Registration of cruciate ligament injuries in Norwegian top level team handball. A prospective study covering two seasons. Scand J Med Sci Sports 1997, 7:289-292.

7. Arendt E, Dick R: Knee injury patterns among men and women in collegiate basketball and soccer. NCAA data and review of literature. Am J Sports Med 1995, 23:694-701.

8. Agel J, Arendt EA, Bershadsky B: Anterior cruciate ligament injury in national collegiate athletic association basketball and soccer: a 13-year review. Am J Sports Med 2005, 33:524-530.

9. Templeton KJ, Hame SL, Hannafin JA, Griffin LY, Tosi LL, Shields NN: Sports injuries in women: sex- and gender-based differences in etiology and prevention. Instr Course Lect 2008, 57:539-552.

10. Lohmander LS, Ostenberg A, Englund M, Roos H: High prevalence of knee osteoarthritis, pain, and functional limitations in female soccer players 
twelve years after anterior cruciate ligament injury. Arthritis Rheum 2004, 50:3145-3152.

11. Englund M, Lohmander LS: Risk factors for symptomatic knee osteoarthritis fifteen to twenty-two years after meniscectomy. Arthritis Rheum 2004 50:2811-2819.

12. von Porat $A$, Roos $E M$, Roos $\mathrm{H}$ : High prevalence of osteoarthritis 14 years after an anterior cruciate ligament tear in male soccer players: a study of radiographic and patient relevant outcomes. Ann Rheum Dis 2004, 63:269-273

13. Gelber AC, Hochberg MC, Mead LA, Wang NY, Wigley FM, Klag MJ: Joint injury in young adults and risk for subsequent knee and hip osteoarthritis. Ann Intern Med 2000, 133:321-328.

14. Kessler MA, Behrend H, Henz S, Stutz G, Rukavina A, Kuster MS: Function, osteoarthritis and activity after ACL-rupture: 11 years follow-up results of conservative versus reconstructive treatment. Knee Surg Sports Traumatol Arthrosc 2008, 16:442-448.

15. Cooper C, Snow S, McAlindon TE, Kellingray S, Stuart B, Coggon D, Dieppe PA: Risk factors for the incidence and progression of radiographic knee osteoarthritis. Arthritis Rheum 2000, 43:995-1000.

16. Thelin N, Holmberg S, Thelin A: Knee injuries account for the sports-related increased risk of knee osteoarthritis. Scand J Med Sci Sports 2006, 16:329-333.

17. Hill CL, Seo GS, Gale D, Totterman S, Gale ME, Felson DT: Cruciate ligament integrity in osteoarthritis of the knee. Arthritis Rheum 2005, 52:794-799.

18. Amin S, Guermazi A, Lavalley MP, Niu J, Clancy M, Hunter DJ, Grigoryan M, Felson DT: Complete anterior cruciate ligament tear and the risk for cartilage loss and progression of symptoms in men and women with knee osteoarthritis. Osteoarthritis Cartilage 2008, 16:897-902

19. Englund M, Roos EM, Lohmander LS: Impact of type of meniscal tear on radiographic and symptomatic knee osteoarthritis: a sixteen-year followup of meniscectomy with matched controls. Arthritis Rheum 2003, 48:2178-2187

20. Ding C, Martel-Pelletier J, Pelletier JP, Abram F, Raynauld JP, Cicuttini F, Jones $\mathrm{G}:$ Meniscal tear as an osteoarthritis risk factor in a largely nonosteoarthritic cohort: a cross-sectional study. J Rheumatol 2007, 34:776-784

21. Roos H, Lauren M, Adalberth T, Roos EM, Jonsson K, Lohmander LS: Knee osteoarthritis after meniscectomy: prevalence of radiographic changes after twenty-one years, compared with matched controls. Arthritis Rheum 1998, 41:687-693.

22. Neuman P, Englund M, Kostogiannis I, Friden T, Roos H, Dahlberg LE: Prevalence of tibiofemoral osteoarthritis 15 years after nonoperative treatment of anterior cruciate ligament injury: a prospective cohort study. Am J Sports Med 2008, 36:1717-1725.

23. Felson DT, Zhang Y: An update on the epidemiology of knee and hip osteoarthritis with a view to prevention. Arthritis Rheum 1998, 41:1343-1355

24. Sitler M, Ryan J, Hopkinson W, Wheeler J, Santomier J, Kolb R, Polley D: The efficacy of a prophylactic knee brace to reduce knee injuries in football. A prospective, randomized study at West Point. Am J Sports Med 1990, 18:310-315.

25. Hewson GF Jr, Mendini RA, Wang JB: Prophylactic knee bracing in college football. Am J Sports Med 1986, 14:262-266.

26. Hansen BL, Ward JC, Diehl RC: The preventive use of the Anderson Knee Stabilizer in football. Physician Sportsmed 1985, 13:75-81.

27. Rovere GD, Haupt HA, Yates CS: Prophylactic knee bracing in college football. Am J Sports Med 1987, 15:111-116.

28. Albright JP, Powell JW, Smith W, Martindale A, Crowley E, Monroe J, Miller R, Connolly J, Hill BA, Miller D, et al.: Medial collateral ligament knee sprains in college football. Effectiveness of preventive braces. Am J Sports Med 1994, 22:12-18.

29. Zemper E: A two year prospective study of prophylactic knee braces in a national sample of college football players. Sports Train Med Rehabil 1990:287-296

30. Teitz CC, Hermanson BK, Kronmal RA, Diehr PH: Evaluation of the use of braces to prevent injury to the knee in collegiate football players. J Bone Joint Surg Am 1987, 69:2-9.

31. Rishiraj N, Taunton JE, Lloyd-Smith R, Woollard R, Regan W, Clement DB: The potential role of prophylactic/functional knee bracing in preventing knee ligament injury. Sports Med 2009, 39:937-960.

32. Ekstrand J, Hagglund M, Fuller CW: Comparison of injuries sustained on artificial turf and grass by male and female elite football players. Scand $J$ Med Sci Sports 2010 [Epub ahead of print].

33. Steffen K, Andersen TE, Bahr R: Risk of injury on artificial turf and natural grass in young female football players. Br J Sports Med 2007, 41 Suppl 1:i33-37.

34. Fuller CW, Dick RW, Corlette J, Schmalz R: Comparison of the incidence, nature and cause of injuries sustained on grass and new generation artificial turf by male and female football players. Part 2: training injuries. Br J Sports Med 2007, 41 Suppl 1:i27-32.

35. Powell JW, Schootman M: A multivariate risk analysis of selected playing surfaces in the National Football League: 1980 to 1989. An epidemiologic study of knee injuries. Am J Sports Med 1992, 20:686-694.

36. Olsen OE, Myklebust G, Engebretsen L, Holme I, Bahr R: Relationship between floor type and risk of ACL injury in team handball. Scand J Med SC Sports 2003, 13:299-304

37. Pasanen K, Parkkari J, Rossi L, Kannus P: Artificial playing surface increases the injury risk in pivoting indoor sports: a prospective one-season followup study in Finnish female floorball. Br J Sports Med 2008, 42:194-197.

38. Orchard JW, Powell JW: Risk of knee and ankle sprains under various weather conditions in American football. Med Sci Sports Exerc 2003, 35:1118-1123.

39. Orchard J, Seward H, McGivern J, Hood S: Intrinsic and extrinsic risk factors for anterior cruciate ligament injury in Australian footballers. Am J Sports Med 2001, 29:196-200.

40. Dowling AV, Corazza S, Chaudhari AM, Andriacchi TP: Shoe-surface friction influences movement strategies during a sidestep cutting task: implications for anterior cruciate ligament injury risk. Am J Sports Med 2010, 38:478-485.

41. Hewett TE, Torg JS, Boden BP: Video analysis of trunk and knee motion during non-contact anterior cruciate ligament injury in female athletes: lateral trunk and knee abduction motion are combined components of the injury mechanism. Br J Sports Med 2009, 43:417-422.

42. Boden BP, Torg JS, Knowles SB, Hewett TE: Video analysis of anterior cruciate ligament injury: abnormalities in hip and ankle kinematics. Am J Sports Med 2009, 37:252-259.

43. Krosshaug T, Nakamae A, Boden BP, Engebretsen L, Smith G, Slauterbeck JR, Hewett TE, Bahr R: Mechanisms of anterior cruciate ligament injury in basketball: video analysis of 39 cases. Am J Sports Med 2007, 35:359-367.

44. Hewett TE, Lynch TR, Ford KR, Gwin RC, Heidt RS Jr, Myer GD: Multiple risk factors related to familial predisposition to anterior cruciate ligament injury: fraternal twin sisters with anterior cruciate ligament ruptures. $\mathrm{Br} J$ Sports Med 2010 [Epub ahead of print]

45. Zazulak BT, Hewett TE, Reeves NP, Goldberg B, Cholewicki J: The effects of core proprioception on knee injury: a prospective biomechanicalepidemiological study. Am J Sports Med 2007, 35:368-373.

46. Hewett TE, Ford KR, Myer GD: Anterior cruciate ligament injuries in female athletes: Part 2, a meta-analysis of neuromuscular interventions aimed at injury prevention. Am J Sports Med 2006, 34:490-498.

47. Pollard CD, Sigward SM, Ota S, Langford K, Powers CM: The influence of in-season injury prevention training on lower-extremity kinematics during landing in female soccer players. Clin J Sport Med 2006, 16:223-227.

48. Lephart SM, Abt JP, Ferris CM, Sell TC, Nagai T, Myers JB, Irrgang JJ: Neuromuscular and biomechanical characteristic changes in high school athletes: a plyometric versus basic resistance program. Br J Sports Med 2005, 39:932-938.

49. Myer GD, Ford KR, Brent JL, Hewett TE: Differential neuromuscular training effects on ACL injury risk factors in"high-risk" versus "low-risk" athletes. BMC Musculoskelet Disord 2007 8:39.

50. Gilchrist J, Mandelbaum BR, Melancon H, Ryan GW, Silvers HJ, Griffin LY, Watanabe DS, Dick RW, Dvorak J: A randomized controlled trial to prevent noncontact anterior cruciate ligament injury in female collegiate soccer players. Am J Sports Med 2008, 36:1476-1483.

51. Pasanen K, Parkkari J, Pasanen M, Hiilloskorpi H, Makinen T, Jarvinen M, Kannus P: Neuromuscular training and the risk of leg injuries in female floorball players: cluster randomised controlled study. BMJ 2008, 337:96-99.

52. Soligard T, Myklebust G, Steffen K, Holme I, Silvers H, Bizzini M, Junge A, Dvorak J, Bahr R, Andersen TE: Comprehensive warm-up programme to prevent injuries in young female footballers: cluster randomised controlled trial. BMJ 2008, 337:a2469.

53. Emery CA, Rose MS, McAllister JR, Meeuwisse WH: A prevention strategy to 
reduce the incidence of injury in high school basketball: a cluster randomized controlled trial. Clin J Sport Med 2007, 17:17-24

54. Mandelbaum BR, Silvers HJ, Watanabe DS, Knarr JF, Thomas SD, Griffin LY, Kirkendall DT, Garrett W Jr: Effectiveness of a neuromuscular and proprioceptive training program in preventing anterior cruciate ligament injuries in female athletes: 2-year follow-up. Am J Sports Med 2005, 33:1003-1010.

55. Hewett TE, Lindenfeld TN, Riccobene JV, Noyes FR: The effect of neuromuscular training on the incidence of knee injury in female athletes. A prospective study. Am J Sports Med 1999, 27:699-706.

56. Engebretsen AH, Myklebust G, Holme I, Engebretsen L, Bahr R: Prevention of injuries among male soccer players: a prospective, randomized intervention study targeting players with previous injuries or reduced function. Am J Sports Med 2008, 36:1052-1060

57. Steffen $K$, Myklebust $G$, Olsen OE, Holme I, Bahr R: Preventing injuries in female youth football - a cluster-randomized controlled trial. Scand J Med SciSports 2008, 18:605-614

58. Bahr R: ACL injuries - problem solved? Br J Sports Med 2009, 43:313-314

59. Englund $M$ : The role of biomechanics in the initiation and progression of OA of the knee. Best Pract Res Clin Rheumatol 2010, 24:39-46.

60. Sharma L, Song J, Felson DT, Cahue S, Shamiyeh E, Dunlop DD: The role of knee alignment in disease progression and functional decline in knee osteoarthritis. JAMA 2001, 286:188-195.

61. Brouwer RW, van Raaij TM, Bierma-Zeinstra SMA, Verhagen AP, Jakma TTSC, Verhaar JAN: Osteotomy for treating knee osteoarthritis. Cochrane Database Syst Rev 2007: CD004019.

62. Allen CR, Wong EK, Livesay GA, Sakane M, Fu FH, Woo SL: Importance of the medial meniscus in the anterior cruciate ligament-deficient knee. J Orthop Res 2000, 18:109-115.

63. Shoemaker SC, Markolf KL: The role of the meniscus in the anteriorposterior stability of the loaded anterior cruciate-deficient knee. Effects of partial versus total excision. J Bone Joint Surg Am 1986, 68:71-79.

64. Walker PS, Erkman MJ: The role of the menisci in force transmission across the knee. Clin Orthop Relat Res 1975, 109:184-192.

65. Chaudhari AM, Briant PL, Bevill SL, Koo S, Andriacchi TP: Knee kinematics, cartilage morphology, and osteoarthritis after ACL injury. Med Sci Sports Exerc 2008, 40:215-222

66. Ageberg $\mathrm{E}$ : Consequences of a ligament injury on neuromuscular function and relevance to rehabilitation - using the anterior cruciate ligamentinjured knee as model. J Electromyogr Kinesiol 2002, 12:205-212.

67. Hurley MV, Jones DW, Wilson D, Newham DJ: Rehabilitation of quadriceps inhibited due to isolated rupture of the anterior cruciate ligament. J Orthop Rheumatol 1992:145-154

68. Newham DJ, Hurley MV, Jones DW: Ligamentous knee injuries and muscle inhibition. J Orthop Rheumatol 1989:163-173.

69. Wojtys EM, Huston L: Longitudinal effects of anterior cruciate ligament injury and patellar tendon autograft reconstruction on neuromuscular performance. Am J Sports Med 2000, 28:336-344.

70. Valeriani M, Restuccia D, DiLazzaro V, Franceschi F, Fabbriciani C, Tonali P: Central nervous system modifications in patients with lesion of the anterior cruciate ligament of the knee. Brain 1996, 119:1751-1762.

71. Felson DT: Risk factors for osteoarthritis: understanding joint vulnerability. Clin Orthop Relat Res 2004, Oct(427 Suppl):S16-21.

72. Corrigan JP, Cashman WF, Brady MP: Proprioception in the cruciate deficient knee. J Bone Joint Surg Br 1992, 74:247-250.

73. Beard DJ, Kyberd PJ, Fergusson CM, Dodd CA: Proprioception after rupture of the anterior cruciate ligament. An objective indication of the need for surgery? J Bone Joint Surg Br 1993, 75:311-315.

74. Borsa PA, Lephart SM, Irrgang JJ, Safran MR, Fu FH: The effects of joint position and direction of joint motion on proprioceptive sensibility in anterior cruciate ligament-deficient athletes. Am J Sports Med 1997, 25:336-340

75. Lysholm M, Ledin T, Odkvist LM, Good L: Postural control - a comparison between patients with chronic anterior cruciate ligament insufficiency and healthy individuals. Scand J Med Sci Sports 1998, 8:432-438.

76. Hurley MV, Jones DW, Newham DJ: Arthrogenic quadriceps inhibition and rehabilitation of patients with extensive traumatic knee injuries. Clin SC (Lond) 1994, 86:305-310.

77. Palmieri-Smith RM, Thomas AC: A neuromuscular mechanism of posttraumatic osteoarthritis associated with ACL injury. Exerc Sport Sci Rev 2009, 37:147-153.
78. Smith RL, Carter DR, Schurman DJ: Pressure and shear differentially alter human articular chondrocyte metabolism: a review. Clin Orthop Relat Res 2004, Oct(427 Suppl):S89-95.

79. Smith RL, Trindade MC, Ikenoue T, Mohtai M, Das P, Carter DR, et al.: Effects of shear stress on articular chondrocyte metabolism. Biorheology 2000, 37:95-107.

80. Meuffels DE, Favejee MM, Vissers MM, Heijboer MP, Reijman M, Verhaar JA: Ten year follow-up study comparing conservative versus operative treatment of anterior cruciate ligament ruptures. A matched-pair analysis of high level athletes. Br I Sports Med 2009, 43:347-351.

81. Georgoulis AD, Papadonikolakis A, Papageorgiou CD, Mitsou A, Stergiou N: Three-dimensional tibiofemoral kinematics of the anterior cruciate ligament-deficient and reconstructed knee during walking. Am J Sports Med 2003, 31:75-79.

82. Scanlan SF, Chaudhari AM, Dyrby CO, Andriacchi TP: Differences in tibial rotation during walking in $\mathrm{ACL}$ reconstructed and healthy contralateral knees. J Biomech 2010, 43:1817-1822.

83. Andriacchi TP, Mundermann A, Smith RL, Alexander EJ, Dyrby CO, Koo S: A framework for the in vivo pathomechanics of osteoarthritis at the knee. Ann Biomed Eng 2004, 32:447-457.

84. Scanlan SF, Blazek K, Chaudhari AM, Safran MR, Andriacchi TP: Graft orientation influences the knee flexion moment during walking in patients with anterior cruciate ligament reconstruction. Am J Sports Med 2009, 37:2173-2178.

85. Keays SL, Bullock-Saxton JE, Keays AC, Newcombe PA, Bullock MI: A 6-year follow-up of the effect of graft site on strength, stability, range of motion, function, and joint degeneration after anterior cruciate ligament reconstruction: patellar tendon versus semitendinosus and Gracilis tendon graft. Am J Sports Med 2007, 35:729-739.

86. Sajovic M, Vengust V, Komadina R, Tavcar R, Skaza K: A prospective, randomized comparison of semitendinosus and gracilis tendon versus patellar tendon autografts for anterior cruciate ligament reconstruction: five-year follow-up. Am J Sports Med 2006, 34:1933-1940.

87. Pinczewski LA, Lyman J, Salmon LJ, Russell VJ, Roe J, Linklater J: A 10-year comparison of anterior cruciate ligament reconstructions with hamstring tendon and patellar tendon autograft: a controlled, prospective trial. Am Sports Med 2007, 35:564-574.

88. Hurd WJ, Axe MJ, Snyder-Mackler L: A 10-year prospective trial of a patient management algorithm and screening examination for highly active individuals with anterior cruciate ligament injury: Part 2, determinants of dynamic knee stability. Am J Sports Med 2008, 36:48-56.

89. Fitzgerald GK, Axe MJ, Snyder-Mackler L: A decision-making scheme for returning patients to high-level activity with nonoperative treatment after anterior cruciate ligament rupture. Knee Surg Sports Traumatol Arthrosc 2000, 8:76-82

90. Kirkley A, Birmingham TB, Litchfield RB, Giffin JR, Willits KR, Wong CJ, Feagan BG, Donner A, Griffin SH, D'Ascanio LM, Pope JE, Fowler PJ: A randomized trial of arthroscopic surgery for osteoarthritis of the knee. N Engl J Med 2008, 359:1097-1107.

91. Herrlin S, Hallander M, Wange P, Weidenhielm L, Werner S: Arthroscopic or conservative treatment of degenerative medial meniscal tears: a prospective randomised trial. Knee Surg Sports Traumatol Arthrosc 2007, 15:393-401.

92. Moseley JB, O'Malley K, Petersen NJ, Menke TJ, Brody BA, Kuykendall DH, Hollingsworth JC, Ashton CM, Wray NP: A controlled trial of arthroscopic surgery for osteoarthritis of the knee. NEngl J Med 2002, 347:81-88.

93. Fairbank TJ: Knee joint changes after meniscectomy. J Bone Joint Surg Am 1948, 30B:664-670.

94. Felson DT: Arthroscopy as a treatment for knee osteoarthritis. Best Practice Res Clin Rheumatol 2010, 24:47-50.

95. Trees $\mathrm{AH}$, Howe TE, Dixon J, White L: Exercise for treating isolated anterior cruciate ligament injuries in adults. Cochrane Database Syst Rev 2005:CD005316

96. Trees AH, Howe TE, Grant M, Gray HG: Exercise for treating anterior cruciate ligament injuries in combination with collateral ligament and meniscal damage of the knee in adults. Cochrane Database Syst Rev 2007:CD005961.

97. Moksnes H, Risberg MA: Performance-based functional evaluation of nonoperative and operative treatment after anterior cruciate ligament injury. Scand J Med Sci Sports 2009, 19:345-355.

98. Daniel DM, Stone ML, Dobson BE, Fithian DC, Rossman DJ, Kaufman KR: Fate of the ACL-injured patient. A prospective outcome study. Am J Sports Med 
1994, 22:632-644.

99. Frobell RB, Roos EM, Roos HP, Ranstam J, Lohmander LS: A randomized trial of treatment for acute anterior cruciate ligament tears. N Eng/ J Med 2010, 363:331-342.

100. Roos EM: Joint injury causes knee osteoarthritis in young adults. Curr Opin Rheumatol 2005, 17:195-200.

101. Becker R, Berth A, Nehring M, Awiszus F: Neuromuscular quadriceps dysfunction prior to osteoarthritis of the knee. J Orthop Res 2004, 22:768-773.

102. Thorstensson CA, Petersson IF, Jacobsson LT, Boegard TL, Roos EM: Reduced functional performance in the lower extremity predicted radiographic knee osteoarthritis five years later. Ann Rheum Dis 2004, 63:402-407.

103. Roos EM, Dahlberg L: Positive effects of moderate exercise on glycosaminoglycan content in knee cartilage: a four-month, randomized controlled trial in patients at risk of osteoarthritis. Arthritis Rheum 2005, 52:3507-3514

104. Kessler MA, Glaser C, Tittel S, Reiser M, Imhoff AB: Recovery of the menisci and articular cartilage of runners after cessation of exercise: additional aspects of in vivo investigation based on 3-dimensional magnetic resonance imaging. Am J Sports Med 2008, 36:966-970.

105. Brama PA, TeKoppele JM, Bank RA, Barneveld A, van Weeren PR: Development of biochemical heterogeneity of articular cartilage: influences of age and exercise. Equine Vet J 2002, 34:265-269.

106. Manninen P, Riihimaki H, Heliovaara M, Suomalainen O: Physical exercise and risk of severe knee osteoarthritis requiring arthroplasty. Rheumatology (Oxford) 2001, 40:432-437.

107. Bass S, Pearce G, Bradney M, Hendrich E, Delmas PD, Harding A, Seeman E: Exercise before puberty may confer residual benefits in bone density in adulthood: studies in active prepubertal and retired female gymnasts. J Bone Miner Res 1998, 13:500-507.

108. Jones G, Ding C, Glisson M, Hynes K, Ma D, Cicuttini F: Knee articular cartilage development in children: a longitudinal study of the effect of sex, growth, body composition, and physical activity. Pediatr Res 2003, 54:230-236.

109. Jones G, Bennell K, Cicuttini FM: Effect of physical activity on cartilage development in healthy kids. Br J Sports Med 2003, 37:382-383.

110. Nicholson S, Dickman K, Maradiegue A: Reducing premature osteoarthritis in the adolescent through appropriate screening. J Pediatr Nurs 2009, 24:69-74.

111. Zebis MK, Andersen LL, Bencke J, Kjaer M, Aagaard P: Identification of athletes at future risk of anterior cruciate ligament ruptures by neuromuscular screening. Am J Sports Med 2009, 37:1967-1973.

112. Padua DA, Marshall SW, Boling MC, Thigpen CA, Garrett WE Jr, Beutler Al: The Landing Error Scoring System (LESS) Is a valid and reliable clinical assessment tool of jump-landing biomechanics: The JUMP-ACL study. Am J Sports Med 2009, 37:1996-2002.

113. FIFA: Prevention of Injuries [http://www.fifa.com/aboutfifa/developing/ medical/newsid=513868.html]

doi:10.1186/ar3113

Cite this article as: Ratzlaff CR, Liang MH: Prevention of injury-related knee osteoarthritis: opportunities for the primary and secondary prevention of knee osteoarthritis. Arthritis Research \& Therapy 2010, 12:215. 